\title{
From America: Manpower, money, and cookbook medicine
}

Matthew H Liang

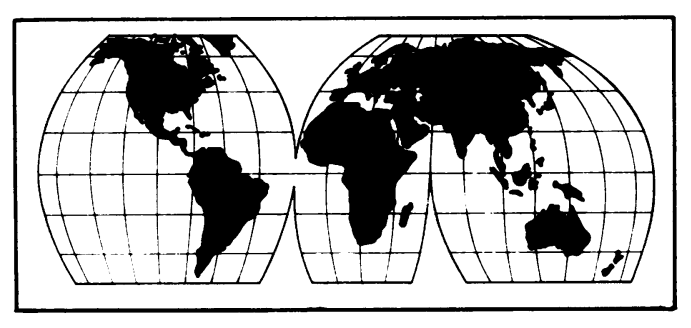

While leaders of principle seem to be winning in Eastern Europe and South Africa, Americans are seemingly observers preoccupied by anxiety about their wellbeing and realisation that the economic boom of the $80 \mathrm{~s}$ is over. Doctors are told that health care costs continue to grow and eat into corporate profits and that something drastic must be done; the public, on the other hand, wants more health spending not less. Rheumatologists feel vulnerable but are responding through their college.

The Committee on Rheumatology Manpower for the American College of Rheumatology chaired by 'Mo' Reichlin recently concluded that 'a perceived decline in the number and quality of applicants in the past five years' has occurred. This gloomy assessment was based on a survey of United States training programme directors. Ninety eight of 116 American programme directors responded to the committee's survey. Forty three said that the number of applicants to their programme had declined and 35 felt that the quality of applicants was also less. There is, as yet, no drop in the number of fellows entering and graduating, but if present trends continue there will be a decline in quality and probably a decline in members within the next few years. A significant number of programmes may have achieved their desired number of fellows by selecting those of lower perceived quality. This would not be surprising because there has been a $25 \%$ decline in the number of applicants to medical schools and to internal medicine training programmes. The reason for this trend can only be surmised but is believed to be related to the falling status of doctors and the perception of those in practice that medicine has become increasingly subject to monetary considerations, bureaucracy, and control by administrators. Easier lifestyles with shorter training requirements and higher financial incentives certainly influence many to turn away from careers in medicine. These factors influence those who might pursue academic careers as do the gloomy funding prospects and the pessimism of role models.

A study 10 years ago by the Graduate Medical Education National Advisory Committee projected a need for 1893 rheumatologists by 1990 . In fact there are currently 3200 rheumatologists, of whom 579 are in full time academic work and 2621 are in practice. Although the committee report projected a surplus of 150000 doctors overall by the end of the century, a recent study suggests that no such surplus will occur. ${ }^{1}$

The number of academic rheumatologists also seems to be levelling off. Between 1972 and 1985 the accredited training programme grew from 100 to 116 , but the number has remained unchanged since. Between 1976 and 1988 about 160 rheumatologists graduated each year. Based on a number of assumptions, the number retiring will equal the number of new rheumatologists entering practice between the years 2000 and 2005 , with 3161 in practice and 729 in academic positions.

On a brighter note, the United States Congress approved a resource based relative value scale payment system for Medicare. This payment system bases doctor's fees on a more rational explicit basis and differs from the current system of 'customary, prevailing, and reasonable fees'. It attempts to take into account, time, mental effort, judgment, physical effort, and technical skill necessary for a service, stress felt by the doctor, income lost while training for a specialty, and overhead costs. The study funded by the Health Insurance Commission on Financing Administration was contracted to the Harvard School of Public Health. Representatives from many but not all specialties met over the course of three years to develop the resource based relative value scale. Problems seen by multiple specialists, such as low back pain seen by an orthopaedic surgeon, a neurosurgeon, a rehabilitation expert, a rheumatologist, a general practitioner, a general internist, etc were chosen to establish a linkage between various subspecialties. Vignettes were constructed around these problems and used in a telephone survey of representative specialists in each field. The results of the survey were used to develop the weight to be placed on each component of the scale. Dr Arthur Weaver and I represented the American College of Rheumatology, which allowed the College to educate the doctors being surveyed about the process of developing the scale. Of all specialty groups surveyed, rheumatologists were the most consistent in estimating the factors used to develop the scale. Transition to a resource based payment system begins in 1992, and will be phased in over five years. What the actual reimbursement will be is unknown as a conversion factor of these relative value scales is yet to be constructed. There were losers and winners in the exercise and some specialties such as orthopaedic surgery had their potential fees reduced; rheumatologists had theirs increased.

Finally, by Congressional fiat in 1989, the Agency for Health Care Policy and Research, comparable with the Food and Drug Administration, has been established to enhance the 'quality, appropriateness, and effectiveness of health care services'. In addition to other functions, the agency will oversee the development of health care
75 Francis Street Boston, Massachusetts 02115, USA

$M$ H Liang
Harvard Medical School, Multipurpose Arthritis Center, Department of 
guidelines. Practice guidelines have been used in the United States since the 1930s and enable those who pay for health care to reduce discretionary practice, to reduce unnecessary services, and, thereby, to reduce medical costs. The American College of Rheumatology first developed its 'guide lines for reviewers of rheumatic disease care' to assist with insurance claims and medical audits. Although some may view guidelines as cookbook medicine, they are meant to give either data based information or consensus statements on treatment strategies or indications for procedures in a given condition. In the next decade it is expected that the government will oversee the development of guidelines in costly areas of health care, such as the management of myocardial infarction, cataract surgery, and the management of low back pain.

The American College of Rheumatology is developing guidelines on Lyme disease, rheumatoid arthritis, and the use of non-steroidal antiinflammatory drugs and has statements indicating its position on obtaining a rheumatology consultation; the practice of arthroscopy by rheumatologists; direction of physical and occupational therapy services for patients under the care of a rheumatologist; access to rehabilitation for individuals with rheumatic disease; and quantitative bone measurement.
The development of guidelines is long overdue and takes some of the ambiguity out of judging what is appropriate and what is not. Whether they reduce costs is debatable; guidelines on hysterectomy, for example, have not reduced its use. ${ }^{2}$ Although there are often few data on which to base guidelines, formal discussion directed towards a consensus statement can illuminate areas for research, as can the sharing of common experiences and results. If rheumatologists do not take the lead in this effort, clinical decisions may be imposed by administrators. It seems judicious to participate in this process but also to evaluate their impact critically.

One can see our friends and colleagues overseas shaking their heads (as do we) with a certain amount of disapproval or sense of resignation; and seeing perhaps in these three vignettes a vision of events to come in their own country.

1 Schwartz W B, Mendelson D N. No evidence of an emerging physician surplus. $\mathcal{F A M A} 1990 ; 263$ : $557-60$.

2 Lomas J, Anderson G M, Domnick-Pierre K, Vayda E, Enkin $M$ W, Hannah W J. Do practice guidelines guide practice? The effect of a consensus statement on the practice of physicians. $N$ Engl f Med 1989; 321: 1306-11. 